http://jmscr.igmpublication.org/home/ ISSN (e)-2347-176x ISSN (p) 2455-0450 crossref DOI: https://dx.doi.org/10.18535/jmscr/v7i8.35

Journal Of Medical Science And Clinical Research

\title{
Hyponatremic events occurring in Hypertensive Patients while taking Thiazide Diuretic
}

\author{
Authors \\ Sanjay Kumar Thakur ${ }^{1}$, Sukhesh Purush Dhakal ${ }^{1}$, Suresh Nepal ${ }^{1}$, \\ George Bush Jung Katwal ${ }^{2}$, Anil Kumar Sah ${ }^{3}$, Bishnu Dutta Paudel ${ }^{1}$ \\ ${ }^{1}$ Bir Hospital, Kathmandu, Nepal \\ ${ }^{2}$ Annapurna Neurological Institute and Allied Sciences, Kathmandu, Nepal \\ ${ }^{3}$ Annapurna Research Center, Kathmandu, Nepal \\ *Corresponding Author \\ Sanjay Kumar Thakur \\ Bir Hospital, Kathmandu, Nepal
}

\section{Abstract}

Introduction: Hyponatremia is common with thiazide. We evaluated how commonly hyponatremia occurs among Nepalese hypertensive patients while they are kept on thiazide.

Methods: It was a cross sectional study, conducted from 2017-March to 2018-March at Bir hospital and Annapurna Neurological Institute \& Allied Sciences, Kathmandu. Data on demography, Thiazide diuretics, use of other medicines and laboratory investigation were obtained from all the hypertensive patients. Four hundred twenty-three patients who met the inclusion criteria i.e., Adult hypertensive patients while on Thiazide diuretic with or without Ca+ Channel blocker(CCB), with or without Angiotensin Receptor Blocker/Angiotensinogen converting enzyme inhibitor(ARB/ACEI) and taking diet orally were enrolled in this study. Conditions like SIADH (syndrome of Inappropriate Anti Diuretic Hormone), congestive heart failure, liver failure, renal failure, or pneumonia and drugs likely to cause hyponatremia were excluded. Serum osmolality was calculated and patients having normal osmolality i.e., 280-300 mos/l was included. Hyponatremia was categorized based on serum level of sodium as Mild (120-134 mmol/l), Moderate (110$119 \mathrm{mmol} / \mathrm{l})$, and Severe (<110mmol/l and/or Symptoms like seizure, disorientation, lethargy, loss of consciousness). Chi-squared tests were used for comparisons between categorical data and multiple regression analysis was used to measure interrelationships between variables in the study population.

Results: A total of Four hundred twenty-three $(n=423)$ hypertensive patients were included. Hyponatremia was found in $380(89.8 \%)$ cases. We found $2.9 \%$ mild, $74.7 \%$ moderate and $22.4 \%$ severe cases of hyponatremia. Hyponatremia was commonly found among thiazideusers in combination with ARB/ACEI and/or CCB or alone $(254 / 380=66 \%)(p=0.02)$. Hyponatremia was frequent $(57.6 \%)$ among 50-69 years of age $(p=0.001)$. Dietary Salt restriction was practiced by $79.2 \%$ of hyponatremia cases $(p=0.014)($ Table 1$)$.

Conclusion: Hyponatremia was seen frequent among hypertensive patients taking thiazide.

Keywords: Hypertension, Hyponatremia, Thiazide.

\section{Introduction}

Thiazide is widely prescribed cost-effective antihypertensive worldwide. ${ }^{1}$ All-cause mortality benefits equal to ACE inhibitor and calcium channel antagonists. ${ }^{2}$ The risk of hyponatremia is increased by age, conditions that decrease body's 
water excretion, and Intensive physical activities. Thiazide, Amitriptyline, pain medications, recreational drug ecstasy can induce hyponatremia. ${ }^{3}$ Severe hyponatremia may develop long after thiazide initiation. Measuring electrolyte while on prolonged thiazide therapy may be essential when symptoms are suggestive. ${ }^{4}$ A study done by Leung et al, found that 3 of 10 hypertensives who take thiazide develop hyponatremia. Thiazide related hyponatremia is found $60 \%$ higher than non-thiazide treatment which is often ignored. ${ }^{5}$ According to the study, a higher dose of thiazide, Elderly patients and women have a higher risk of developing hyponatremia. ${ }^{6}$ On contrary, Rodenburg et al. concluded in their study that the risk of thiazide induced hyponatremia is decrease with older age. In another study, Thiazide-associated hyponatremia was seen highest among lowest BMI (Body Mass Index): almost 8 times higher. ${ }^{7}$ Thiazide affects the dilution abilities of kidneys causing hyponatremia. ${ }^{7}$

Symptoms of hyponatremia are nausea and malaise, lethargy, decreased level of consciousness, headache, seizures and coma. ${ }^{1}$ severe hyponatremia causes confusion, falls and seizures, and can be fatal. Hyponatraemia necessitating hospital admission is common which suggest monitoring of serum sodium levels periodically while patients are taking thiazide is essential. Mean serum sodium concentration in the total treated population is virtually unchanged by thiazide therapy, implying that thiazide-induced hyponatremia occurs in a susceptible subgroup. So, thiazide-induced hyponatremia is largely unpredictable at the point of thiazide initiation. ${ }^{1}$ Therefore this studyset out to find the magnitude of hyponatremia in hypertensive patients while they were on thiazide treatments of all age group.

\section{Method}

A cross-sectional prospective study was carried out from March 2017 to March 2018 at Bir hospital and Annapurna Neurological Institute \& Allied Sciences. The ethical approval was taken from the ethical review board of the National Academy of Medical Science. During the study period a total 423 adult hypertensive patients who experienced hyponatremia were enrolled. Patients were taking antihypertensive with or without thiazide diuretics. Conditions like congestive heart failure, liver failure, renal failure, or pneumonia and selective serotonin reuptake inhibitors were excluded from the study. ${ }^{8}$

The data were collected on demography, hypertension, details of antihypertensive drugs used and other drugs used, dietary salt restriction, co-morbidities and serum electrolytes reports. Normal reference range of electrolytes considered were as follows: sodium: 135 to $145 \mathrm{mmol} / \mathrm{L}$, potassium: 3.5 to $4.7 \mathrm{mmol} / \mathrm{L}$, chloride: 97 to 108 $\mathrm{mmol} / \mathrm{L}$, calcium: 2.1 to $2.55 \mathrm{mmol} / \mathrm{L}$, Phosphate: 0.84 to $1.45 \mathrm{mmol} / \mathrm{L}$, magnesium: 0.75 to 1.00 $\mathrm{mmol} /$ Hyponatremia were categorized based on biochemical value of sodium as Mild (120-134 $\mathrm{mmol} / \mathrm{l})$, Moderate (110-119 $\mathrm{mmol} / \mathrm{l})$, and Severe (<110 mmol/l +/- associated symptoms like seizure, disorientation, lethargy, loss of consciousness).Statistical analysis was undertaken using standard statistical formulae. Sodium and potassium values in $\mathrm{mmol} / \mathrm{L}$ were expressed as 95\% confidence interval for the mean. Urea results were $\log$ transformed to achieve normal distribution. Chi-squared tests were used for comparing between categorical data. Multiple regression analysis was used to measure interrelationships between variables in the study sample.

\section{Result}

A total of 423 hypertensive patients were included for analysis and in $89.8 \%$ (380) patients were found to have hyponatremia. Among all (380) hyponatremic patients 66 were on $\mathrm{Ca}+$ channel blocker, 38 were on ARB/ACEI, 20 were on both $\mathrm{ARB} / \mathrm{ACEI}$ and $\mathrm{Ca}+$ channel blocker, and 254 patients were on thiazide and ARB/ACEIand/or CCB combinations. Two hyponatremic patients had unknown drug intake because of missing prescription. Biochemical severity with or without 
clinical symptoms of hyponatremia were, $2.9 \%$ mild, $74.7 \%$ moderate and $22.4 \%$ severe grades of hyponatremia. Among all hyponatremia cases; $55.3 \%$ (210/380) were males and 44.7\% (170/380) were females $(\mathrm{p}=0.75)$. There were higher number $(57.6 \%)$ of hyponatremia in age 50-69 years $(\mathrm{p}=0.001)$. Among all cases, $79.2 \%$ subjectively told that they practiced low dietary salt intake $(\mathrm{p}=0.014) \quad$ (Table 1). Among hyponatremia patients, $66.8 \%(254 / 380)$ were on thiazide in combinations with ARBs/ACEI and/or calcium channel blocker or alone. Patients receiving ca+ channel blocker (CCB) were $29.7 \%$ (113/380). However, Patients receiving Thiazide in combination with calcium channel blocker (27/113) were not significantly associated with hyponatremia $(\mathrm{p}>0.05)$.

Table 1. Distribution of hyponatremia patients by Age, Sex, Drug and Salt restriction

\begin{tabular}{|c|c|c|c|c|c|}
\hline & \multicolumn{3}{|c|}{ Hyponatremia } & \multirow[t]{2}{*}{ Total } & \multirow[t]{2}{*}{ P-value } \\
\hline & Mild & Moderate & Sever & & \\
\hline \multicolumn{6}{|l|}{ Sex } \\
\hline Male & $6(54.5 \%)$ & $160(56.3 \%)$ & $44(51.8 \%)$ & $210(55.3 \%)$ & \multirow[t]{2}{*}{0.75} \\
\hline Female & $5(45.5 \%)$ & $124(43.7 \%)$ & $41(48.2 \%)$ & $170(44.7 \%)$ & \\
\hline \multicolumn{6}{|c|}{ Age Group } \\
\hline$<30$ & $1(9.1 \%)$ & $2(0.7 \%)$ & $0(0.0 \%)$ & $3(0.8 \%)$ & \multirow{5}{*}{0.001} \\
\hline $30-49$ & $5(45.5 \%)$ & $32(11.3 \%)$ & $16(18.8 \%)$ & $53(13.9 \%)$ & \\
\hline $50-69$ & $3(27.3 \%)$ & $165(58.1 \%)$ & $51(60.0 \%)$ & $219(57.6 \%)$ & \\
\hline $70-89$ & $2(18.2 \%)$ & $83(29.2 \%)$ & $18(21.2 \%)$ & $103(27.1 \%)$ & \\
\hline$>90$ & $0(0.0 \%)$ & $2(0.7 \%)$ & $0(0.0 \%)$ & $2(0.5 \%)$ & \\
\hline \multicolumn{6}{|c|}{ Salt Restriction } \\
\hline No & $6(54.5 \%)$ & $59(20.8 \%)$ & $14(16.5 \%)$ & $79(20.8 \%)$ & \multirow{2}{*}{0.014} \\
\hline Yes & $5(45.5 \%)$ & $225(79.2 \%)$ & $71(83.5 \%)$ & $301(79.2 \%)$ & \\
\hline \multicolumn{6}{|c|}{\begin{tabular}{|l|} 
Thiazide \\
\end{tabular}} \\
\hline No & $7(63.6 \%)$ & $98(34.5 \%)$ & $21(24.7 \%)$ & $126(33.2 \%)$ & \multirow[b]{2}{*}{0.02} \\
\hline Yes & $4(36.4 \%)$ & $186(65.5 \%)$ & $64(75.3 \%)$ & $254(66.8 \%)$ & \\
\hline \multicolumn{6}{|c|}{ Ca+ Channel Blocker } \\
\hline No & $6(54.5 \%)$ & $204(71.8 \%)$ & $57(67.1 \%)$ & $267(70.3 \%)$ & \\
\hline Yes & $5(45.5 \%)$ & $80(28.2 \%)$ & $28(32.9 \%)$ & $113(29.7 \%)$ & 0.35 \\
\hline \multicolumn{6}{|c|}{ ARB/ACEI } \\
\hline No & $5(45.5 \%)$ & $62(21.8 \%)$ & $14(16.5 \%)$ & $81(16.5 \%)$ & \\
\hline Yes & $6(54.5 \%)$ & $222(78.2 \%)$ & $71(83.5 \%)$ & $299(78.7 \%)$ & 0.80 \\
\hline
\end{tabular}

Table 2: Subgroup analysis of thiazide and combination drugs causing hyponatremia $(\mathrm{N}=254)$

\begin{tabular}{|l|c|c|}
\hline Drug name & Number of cases & $\mathrm{p}$-value \\
\hline Thiazide only & 1 & - \\
\hline Thiazide +CCB & 12 & 0.346 \\
\hline Thiazide + ARB/ACEI & 226 & 0.016 \\
\hline Thiazide + ARB/ACEI + CCB & 15 & 0.163 \\
\hline Thiazide + any other drugs & 0 & - \\
\hline
\end{tabular}

\section{Discussion}

Thiazide induced hyponatremia has a significant clinical impact, such as delirium and falls, which limits the use of these potent antihypertensive agents. ${ }^{9}$ Results of the study i.e. Hyponatremia was more commonly seen in patients taking thiazide $66 \%$ are similar to most of the other similar studies done on thiazide induced hyponatremia in hypertension. A study done by
Chow $\mathrm{KM}$ et al derived similar conclusion that Hyponatremia is a common problem after thiazide therapy. ${ }^{10}$ Extra caution and close monitoring are warranted when prescribing thiazides for elderly patients ${ }^{10}$ with low body mass. ${ }^{11}$ A study done on 2613 patients found that $33 \%$ of patients exposed to thiazides develop hyponatremia. The number needed to harm (to result in one excess case of incident hyponatremia in 5 years) was 15.02 (95\% 
CI, 7.88-160.30). ${ }^{10}$

Regarding age and sex predisposition of thiazide induced hyponatremia the current study showed no such predisposition. However, this study showed that age between 50-69 years was more prone to develop hyponatremia when exposed to thiazide. Regarding sex men were found more risky to develop hyponatremia than females while on thiazide but this finding was not statistically significant. However, few other studies showed that Thiazide-associated hyponatremia were more commonly found in elderly especially with low body mass or low-sodium diet. ${ }^{11}$ contrary to this finding, one other study reported that only $10 \%$ of elderly women had diuretic-associated hyponatremia who received a low dose of hydrochlorothiazide $(12.5 \mathrm{mg} /$ day $)$. It suggested that the effects of thiazides were dosedependent. ${ }^{12}$ Patients in thisstudy mostly used cooking salt in food rather than table salt, the quantification of which was impossible for the individual patients. But, most patients told us that they had practiced either low dietary salt consumption or even had stopped salt intake after the diagnosis of hypertension. Thus, caution should be taken by health workers while prescribing thiazide for hypertension that patients should not completely stop dietary salt intake especially by the elderly patients, although low dietary salt intake is advisable to the hypertensive patients taking non-thiazide treatments for hypertension.

\section{Conclusion}

Hyponatremia was seen more frequently in hypertensive patients taking thiazide diuretic and also in the patients who were on salt restriction and older age group.

\section{Reference}

1. Vandergheynst F, Sakr Y, Felleiter P, Hering R, Groeneveld J, Vanhems P, Taccone FS, Vincent JL. Incidence and prognosis of dysnatremia in critically ill patients: analysis of a large prevalence study. Eur J Clin Investig. 2013; 43:933-48.

https://www.ncbi.nlm.nih.gov/pubmed/238 69476

2. Robertson GL. Antidiuretic hormone. Normal and disordered function. Endocrinol Metab Clin North Am 2001; 30:671-694.

https://www.ncbi.nlm.nih.gov/pubmed/115 71936

3. Sharabi Y, Illan R, Kamari Y, et al. Diuretic induced hyponatremia in elderly hypertensive women. J Hum Hypertense. 2002;16:631-635.

https://www.ncbi.nlm.nih.gov/pubmed/122 14259

4. Neafsey PJ. Thiazides and selective serotonin reuptake inhibitors can induce hyponatremia. Home Health Nurse. 2004; 22:788-790.

https://www.ncbi.nlm.nih.gov/pubmed/155 86063

5. Burton TJ, Salsbury J, Hood S, Brown MJ. Conn's syndrome unmasked by thiazideinduced hypokalemia. $\mathrm{Br} \mathrm{J}$ HospMed 2011; 72: 530-1. https://www.ncbi.nlm.nih.gov/pubmed/220 41837

6. Lalioti M, Zhang J, Volkman HM, Kahle KT, Hoffmann KE,Toka HR, NelsonWilliams C, Ellison DH, Flavell R, Booth CJ,Lu Y, Geller DS, Lifton RP. Wnk 4 controls blood pressure and potassium homeostasis via regulation of mass and activity of the distal convoluted tubule. Nat Genet 2006; 38:1124 32.https://www.ncbi.nlm.nih.gov/pubmed? cmd $=$ link\&linkname=pubmed_pubmed.

7. Glover M, Zuber Am, O'Shaughnessy KM. Hypertension, dietary salt intake, and the role of the thiazide-sensitive sodium chloride transporter NCCT. Cardiovasc Ther 2010; 1:68-76. https://www.ncbi.nlm.nih.gov/pubmed/211 67012 
8. The National Institute of Clinical Excellence (NICE).CG34 Hypertension: Full guideline (new recommendations and the evidence they are based on). Available at: http://guidance.nice.org.uk/CG34/Guidanc e/pdf/English. 2006 [Accessed 5 May 2011].

9. Ruzicka M1, 2, McCormick B1, Magner P1, Ramsay T3, Edwards C1, Bugeja A1, Hire math S1. Pilot Feasibility Study. Thiazide diuretic-causeshyponatremia in the elderly hypertensive: will a bottle of Nepro a day keep hyponatremia and the doctor away? Study protocol for a proofof- concept feasibility trial. E Collection 2018 Apr 6; 4: 71.doi: 10.1186/s40814018-0263.

https://www.ncbi.nlm.nih.gov/pmc/articles /PMC5889541/

10. Chow KM1, Szeto CC, Wong TY, Leung $\mathrm{CB}$, Li PK. Risk factors for thiazideinduced hyponatremia. QJM. 2003 Dec; 96(12):911-7.

https://www.ncbi.nlm.nih.gov/pubmed/146 31057

11. C M Byatt et al. Diuretics and electrolyte disturbances in 1000 consecutive geriatric admissions. Journal of the Royal Society of Medicine.1990November (83):704708.https://www.ncbi.nlm.nih.gov/pmc/art icles/PMC1292918/pdf/jrsocmed001300030 .

12. George Liamisetal.Thiazide-associated hyponatremia in the elderly: what the clinician needs to know. J Geriatr Cardiol. 2016 Feb; 13(2): 175-182.doi: $10.11909 /$ j.issn.1671-

5411.2016.02.001.PMCID:PMC 4854958.PMID: 27168745. https://www.ncbi.nlm.nih.gov/pmc/articles /PMC4854958. 